\title{
Dynamic contrast-enhanced MR and PET/ CT findings of uterine sarcomatoid carcinoma: a case report
}

\author{
Tingting Cui, Yanfang Jin, Bin Li, Jiyuan Li and Yunlong Yue* (i)
}

\begin{abstract}
Background: Sarcomatoid carcinoma (SC) is a malignant tumour composed of spindle cells. The incidence of SC is low, especially in the uterus. The imaging features of uterine sarcomatoid carcinoma (USC) are rarely reported. We report a case of USC and discuss the dynamic contrast-enhanced MR (DCE-MR) and PET/CT findings.

Case presentation: A 69-year-old woman presented to the Department of Gynaecology with vaginal bleeding. Ultrasound examination discovered a heterogeneous mass in the cervix. Then, MRI examination of the pelvis was performed. On T2-weighted images, the uterus was replaced by an ill defined and diffuse lesion with inhomogeneous intensity. On T1-weighted images, the lesion appeared with signal hypointensity and was heterogeneously enhanced with contrast material. Additionally, enlarged lymph nodes were found in the pelvic cavity. PET/CT demonstrated high uptake in the region of the uterus and pelvic lymph nodes, which was consistent with MRI findings. The radiologists diagnosed the patient with malignant uterine lesions. The patient underwent hysterectomy and bilateral adnexectomy with pelvic lymph node dissection. Then, systemic radiotherapy and chemotherapy were performed. USC with lymph node metastasis was diagnosed with the help of immunohistochemical analysis. There was no treatment related complication and no evidence of tumour recurrence at the postoperative 6-month follow-up.
\end{abstract}

Conclusion: MRI and PET/CT features are sufficient to indicate the malignant nature of a USC, but they are not pathognomonic.

Keywords: Uterus, Sarcomatoid carcinoma, MRI, PET-CT

\section{Background}

$\mathrm{SC}$ is a rare spindle cell carcinoma $[1,2]$. It is most commonly found in the lung, followed by the liver, kidney, bladder and gastrointestinal tract [3, 4]. Clinically, SC is an aggressive malignancy with a high rate of metastasis. It responds poorly to treatment and has a poor prognosis (5-year survival rate of $15-42 \%)[1,5]$.

To date, 18 cases of sarcomatoid squamous cell carcinoma of the cervix have been described in the

\footnotetext{
*Correspondence: sjtmrtg@126.com

Department of MR, Beijing Shijitan Hospital, Capital Medical University, Beijing, China
}

English-language literature. However, only two reports have discussed the MRI or PET features of USC. Here, we present a case of pathologically confirmed USC and the accompanying DCE-MRI and PET/CT findings.

\section{Case presentation}

A 69-year-old woman with a past medical history of hypertension, tuberculosis, and meningioma presented with abnormal vaginal bleeding for 10 days as well as fever. Furthermore, her family history was unremarkable. Physical examination revealed a barrel-shaped uterus. The patient felt mild tenderness upon palpation.

C The Author(s). 2020 Open Access This article is licensed under a Creative Commons Attribution 4.0 International License, which permits use, sharing, adaptation, distribution and reproduction in any medium or format, as long as you give appropriate credit to the original author(s) and the source, provide a link to the Creative Commons licence, and indicate if changes were made. The images or other third party material in this article are included in the article's Creative Commons licence, unless indicated otherwise in a credit line to the material. If material is not included in the article's Creative Commons licence and your intended use is not permitted by statutory regulation or exceeds the permitted use, you will need to obtain permission directly from the copyright holder. To view a copy of this licence, visit http://creativecommons.org/licenses/by/4.0/ The Creative Commons Public Domain Dedication waiver (http://creativecommons.org/publicdomain/zero/1.0/) applies to the data made available in this article, unless otherwise stated in a credit line to the data. 
Laboratory studies noted an elevated carbohydrate antigen 125 (CA125) level of $201.1 \mathrm{U} / \mathrm{ml}$, while the carcinoembryonic antigen (CEA) and carbohydrate antigen 19-9 (CA19-9) levels were normal.

The patient underwent a pelvic Two-dimensional ultrasound that showed an enlarged uterus and a heterogeneous mass in the cervix. Then, MRI examination of the pelvis was performed with a 1.5 Tesla MR scanner (Ingenia $1.5 \mathrm{~T}$; Philips Healthcare, The Netherlands). The T2-weighted images showed that the uterus was replaced by an ill defined and diffuse lesion with inhomogeneous intensity. On T1-weighted images, the lesion appeared with hypointensity. The lesion showed invasive growth with enlarged lymph nodes in the pelvic cavity. DCE-MRI demonstrated inhomogeneous enhancement and resulted in a plateaued curve with a prolonged scanning time (Fig. 1). PET/CT fusion images showed abnormal FDG accumulation, with maximum SUVs of 24.8 and 19.3 for the uterus and pelvic lymph node, respectively (Fig. 2). Therefore, uterine malignancy with nodal metastasis was diagnosed.
The patient underwent hysterectomy and bilateral adnexectomy with pelvic lymph node dissection. Macroscopically, the uterus was enlarged with thickened myometrium, which was grey and yellow on the cut surface with poor elasticity and brittle texture. Additionally, some nodules could be seen in the myometrium. Histologically, haematoxylin and eosin (HE) stained sections showed that the uterine tumour was composed of spindle cells and nodal metastasis was confirmed. Immunohistochemical analysis supported the diagnosis of USC (Fig. 3). The patient received postoperative systemic radiotherapy and chemotherapy. The patient remained well and has no evidence of recurrence at the postoperative 6-month follow-up.

\section{Discussion and conclusions}

$\mathrm{SC}$ is an extremely rare malignant tumour of the uterus that has not been listed in the WHO classification as a separate entity. Because of the rarity SC, its differential diagnosis often includes aggressive uterine lesions. As an entity, USC should not be confused with uterine carcinosarcoma. Pathologically, USC is characterized by the
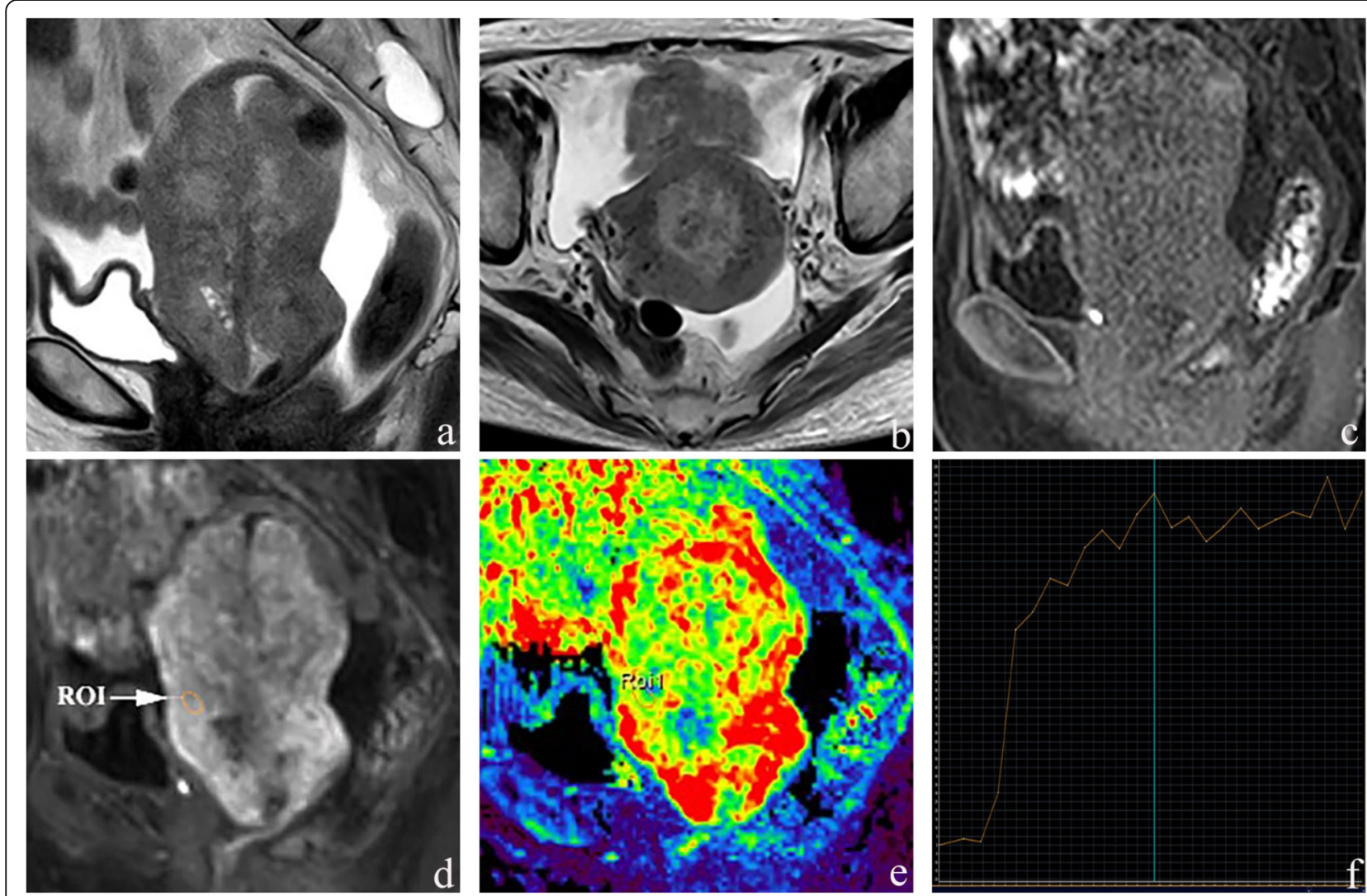

Fig. 1 MRI images. a Sagittal T2-weighted image shows that the uterus was replaced by diffuse inhomogeneous signal intensity. $\mathbf{b}$ Axial T2weighted image shows that the lesion is ill defined and diffusely invades the myometrium. c, d Sagittal T1-weighted image shows the lesion appeared with hypointensity and inhomogeneous enhancement. e Colour perfusion map shows the slightly lower vascularity of the tumour (green area), while the greater vascularity is depicted in red (the normal myometrium). $\mathbf{f}$ The dynamic enhanced curve of the USC: avid enhancement, with both early and persistent enhancement 


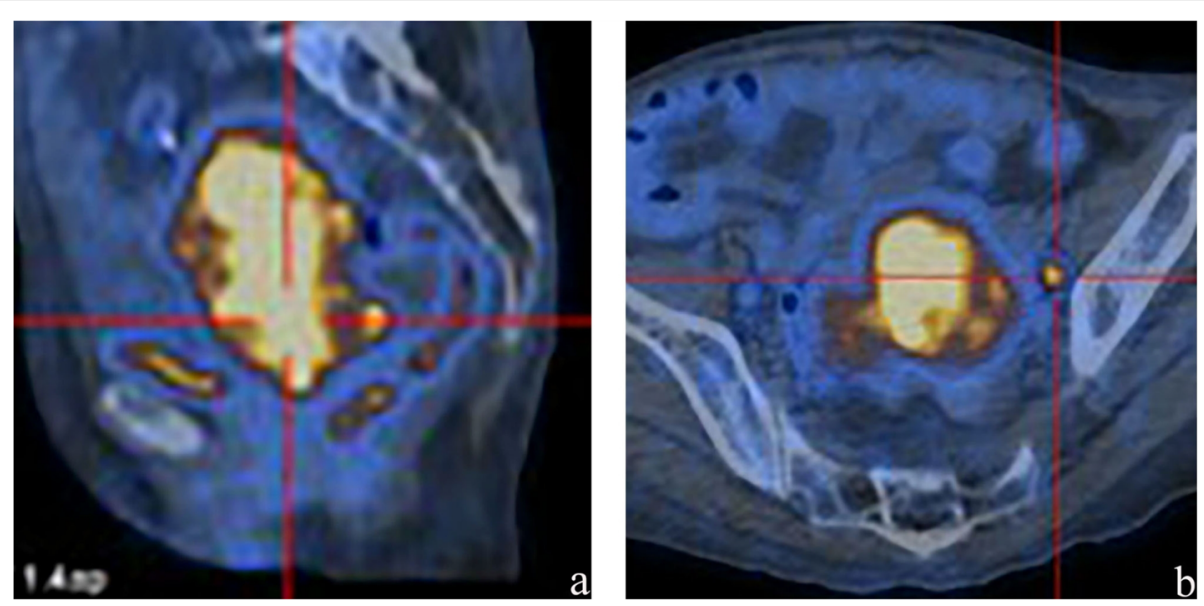

Fig. 2 PET/CT images. a Sagittal PET/CT fusion image shows abnormal FDG accumulation in the uterus, and the SUVmax is 24.8. b Axial PET/CT fusion image shows abnormal FDG accumulation in the pelvic lymph nodes, and the SUVmax is 19.3

presence of spindle cells, showing broad-spectrum epithelial and mesenchymal markers. In contrast to uterine carcinosarcoma, USC does not express malignant heterologous elements, such as chondrosarcoma or osteosarcoma [6-10].

To the best of our knowledge, only two reports have discussed the MRI or PET features of USC in the literature $[11,12]$. Shrivastava et al. found that USC showed hyperintensity on T2WI and isointensity on T1WI similar to cervical mass lesions with extra-uterine extension [11]. Milind et al. described abnormal FDG accumulation of USC in the region of the cervix and the upper vagina by PET, with maximum SUVs of 5.7 and 10.6 for the vagina and the cervix, respectively [12]. In our case, DCE-MRI showed that USC presents with inhomogeneous signal intensity on T2WI and heterogeneous enhancement on T1WI, as well as cystic degeneration and necrosis, and the lesion was diffuse rather than a well-defined mass. PET/CT images showed abnormal FDG accumulation, with maximum SUVs of 24.8 and 19.3 for the uterus and pelvic lymph node, respectively. Our MRI and PET/CT findings of USC were
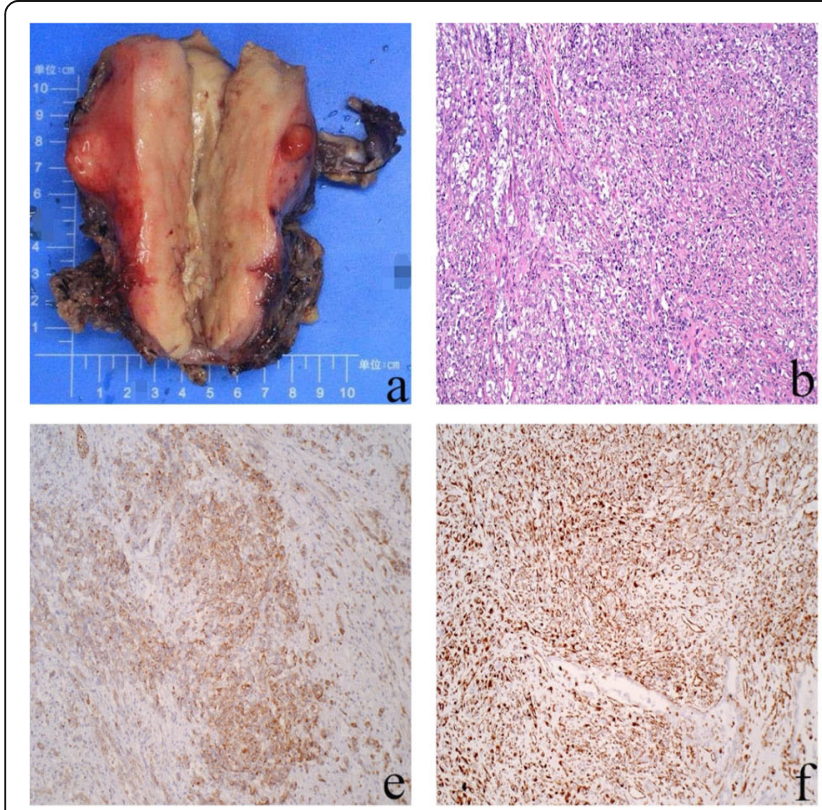
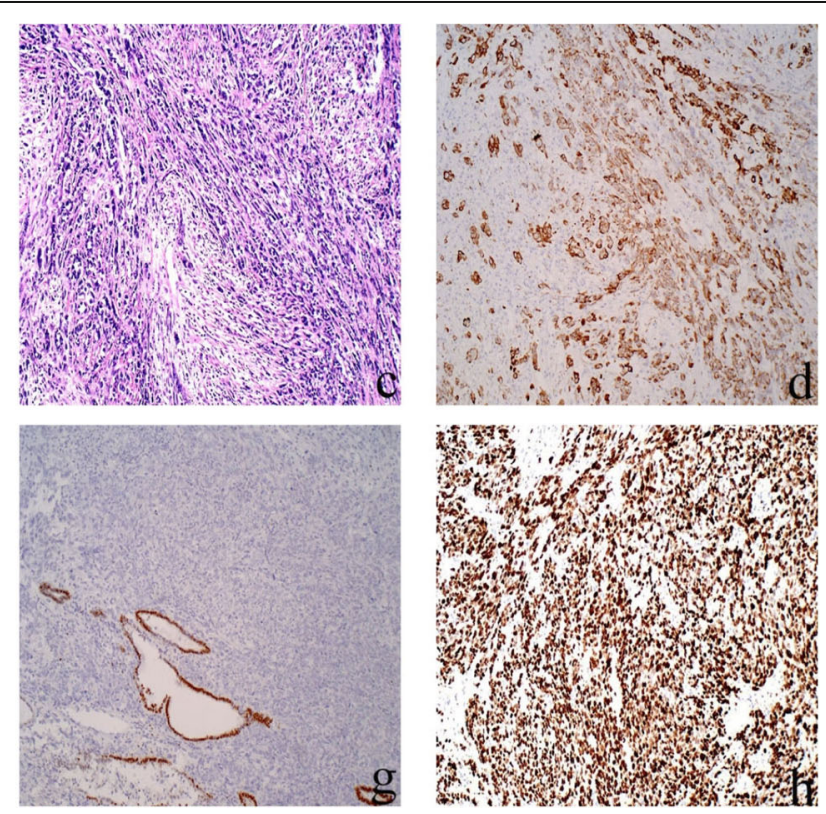

Fig. 3 Gross surgical specimen and photomicrographs. a The enlarged uterus with thickened myometrium. b Spindle cells in the cervix (HE, $x$ 100). $\mathbf{c}$ Spindle cells in the corpus $(H E, \times 100)$. $\mathbf{d}$ Cytoplasmic positive immunoreactivity for CK (original magnification $\times 100)$. e Cytoplasmic positive immunoreactivity for EMA (original magnification $\times 100$ ). $\mathbf{f}$ Cytoplasmic positive immunoreactivity for vimentin (original magnification $\times$ 100). $\mathbf{g}$ Cytoplasmic negative immunoreactivity for PAX-8 (original magnification $\times 100$ ). $\mathbf{h}$ Ki-67 index is $90 \%$ 
different from previous reports and therefore may not be specific for USC.

Distinguishing USC from uterine sarcoma is not possible because these tumours share many imaging characteristics, including heterogeneity, cystic degeneration and necrosis [13-15]. Therefore, the final diagnosis must rely on immunohistochemistry. Although a precise diagnosis of USC could not be established preoperatively, the combination of clinical, MRI and PET/CT findings support the diagnosis of a malignant disease. The patient was operated by doctor with proper expertise followed by adjuvant radiotherapy and chemotherapy. The patient remained well and has no evidence of recurrence at the postoperative 6-month follow-up.

USC is a rare and aggressive tumour, and its imaging features may not be pathognomonic. The recognition of features that are suggestive of a malignant condition is sufficient to assist the surgeon in managing such patients.

\section{Abbreviations}

SC: Sarcomatoid carcinoma; USC: Uterine sarcomatoid carcinoma; DCEMRI: Dynamic contrast-enhanced MR; CA125: Carbohydrate antigen 125; CEA: Carcinoembryonic antigen; CA19-9: Carbohydrate antigen 19-9; HE: Hematoxylin and eosin

\section{Acknowledgements}

The authors are grateful to and thank the patient for her participation and cooperation in our study.

\section{Authors' contributions}

$T T C, Y F J, B L, J Y L$, and $Y L Y$ aided in the gathering of the date, and all participated in either preparing or revising the manuscript. ALL authors have approved the manuscript.

\section{Funding}

The study did not receive any funding by any governmental or private organization.

\section{Availability of data and materials}

The datasets used during the current study are available from the corresponding author on reasonable request.

\section{Ethics approval and consent to participate}

Not applicable.

\section{Consent for publication}

The patient gave her written informed consent for the publication of her data.

\section{Competing interests}

The authors declare that they have no competing interests.

Received: 12 April 2020 Accepted: 22 September 2020

Published online: 06 October 2020

\section{References}

1. Kan A, Guo RP. The prognosis of subsequent surgical treatment in patients with sarcomatoid carcinoma in the liver: a retrospective study. Int J Surg. 2018;55:145-51.

2. Leng Q, Xiang XI, Tang Y, Yang Y, Qiu LI. Primary hepatic sarcomatoid carcinoma: a case report. Exp Ther Med. 2015;10(3):1145-8.

3. Chin S, Kim Z. Sarcomatoid combined hepatocellular-cholangiocarcinoma: a case report and review of literature. Int J Clin Exp Pathol. 2014;7(11):8290-4.
4. Lao XM, Chen DY, Zhang YQ, Xiang J, Guo RP, Lin XJ, Li JQ. Primary carcinosarcoma of the liver: clinicopathologic features of 5 cases and a review of the literature. Am J Surg Pathol. 2007;31(6):817-26.

5. Maneenil K, Xue Z, Liu M, Boland J, Wu F, Stoddard SM, Molina J, Yang P. Sarcomatoid carcinoma of the lung: the Mayo Clinic experience in 127 patients. Clin Lung Cancer. 2018;19(3):e323-33.

6. McCluggage WG. Malignant biphasic uterine tumours: carcinosarcomas or metaplastic carcinomas? J Clin Pathol. 2002;55(5):321-5.

7. Shen ZL, Wang S, Ye YJ, Wang YL, Sun KK, Yang XD, Jiang KW. Carcinosarcoma of pancreas with liver metastasis combined with gastrointestinal stromal tumour of the stomach: is there a good prognosis with the complete resection? Eur J Cancer Care (Engl). 2010;19(1):118-23.

8. Lopez-Garcia MA, Palacios J. Pathologic and molecular features of uterine carcinosarcomas. Semin Diagn Pathol. 2010;27(4):274-86.

9. Terada T. Sarcomatoid squamous cell carcinoma of the uterine cervix. Arch Gynecol Obstet. 2010;282(2):231-2.

10. Brown J, Broaddus R, Koeller M, Burke TW, Gershenson DM, Bodurka DC. Sarcomatoid carcinoma of the cervix. Gynecol Oncol. 2003;90(1):23-8.

11. Shrivastava S, Barmon D, Deka P, Ch Kataki A, Choudhary BK. Sarcomatoid carcinoma of the cervix with foci of malignant melanoma. J Midlife Health. 2014;5(1):41-4.

12. Kumar M, Bahl A, Sharma DN, Agarwal S, Halanaik D, Kumar R, Rath GK. Sarcomatoid squamous cell carcinoma of uterine cervix: pathology, imaging, and treatment. J Cancer Res Ther. 2008;4(1):39-41.

13. Sagebiel TL, Bhosale PR, Patnana M, Faria SC, Devine CE. Uterine Carcinosarcomas. Semin Ultrasound CT MR. 2019:40(4):295-301.

14. Genever AV, Abdi S. Can MRI predict the diagnosis of endometrial carcinosarcoma? Clin Radiol. 2011;66(7):621-4.

15. Hernandez Mateo P, Mendez Fernandez R, Serrano Tamayo E. Uterine sarcoma vs adenocarcinoma: can MRI distinguish between them? Radiologia. 2016;58(3):199-206.

\section{Publisher's Note}

Springer Nature remains neutral with regard to jurisdictional claims in published maps and institutional affiliations.
Ready to submit your research? Choose BMC and benefit from:
- fast, convenient online submission
- thorough peer review by experienced researchers in your field
- rapid publication on acceptance
- support for research data, including large and complex data types
- gold Open Access which fosters wider collaboration and increased citations
- maximum visibility for your research: over $100 \mathrm{M}$ website views per year
At BMC, research is always in progress.
Learn more biomedcentral.com/submissions 